\title{
Classroom Management Strategies for Inclusive Classrooms
}

\author{
Susan Polirstok \\ Special Education, Kean University, Union, NJ, USA \\ Email: polirsts@kean.edu
}

Received 22 April 2015; accepted 15 June 2015; published 19 June 2015

Copyright (C) 2015 by author and Scientific Research Publishing Inc.

This work is licensed under the Creative Commons Attribution International License (CC BY). http://creativecommons.org/licenses/by/4.0/

(c) (i) Open Access

\begin{abstract}
Classrooms in the 21st century have by law become inclusive, typically comprised of general education and special needs students. Included students are those who present with mild to moderate learning and behavioral challenges. They add another layer of complexity to classroom management, requiring teachers to be highly structured, consistent and reinforcing. Teacher fidelity to behavioral expectations that have been established for the classroom is essential. Classroom management strategies discussed include changing the teacher approval to disapproval ratio, using selective ignoring, focusing on structure and routine, increasing student locus of control, de-escalating student aggression and hostility, and limiting the use of punishment. Hands-on strategies are highlighted.
\end{abstract}

Keywords

Reinforcement, Punishment, Selective Ignoring, Locus of Control, Inclusion

\section{Introduction}

Every teacher regardless of where they teach, what they teach, or who they teach, needs to be effective. Nothing less will do, especially in this era of increased accountability. Teachers must demonstrate depth of knowledge in the content area or areas that they will be expected to teach. After all, isn't this assessed by taking and passing standardized examinations for grade and subject matter that serve as requirements for teacher certification? While a given teacher could score highly on a certification examination that tests content knowledge, without a solid grounding in classroom management strategies, the teacher's knowledge cannot be communicated effectively to students who are off-task and engaged in disruptive behaviors. The common denominator that is most closely linked with effective teaching beyond academic content preparation is strong classroom management (Lemov, 2010). 
Most classrooms of today are inclusion classrooms which have a blend of students with special needs and general education students. The students with special needs in inclusive classrooms often present with mild to moderate learning and/or behavioral challenges. For students who might be identified as having learning disabilities, $45 \%$ of the time they also have an attention deficit and struggle with organization and executive function (DuPaul, Gormley, \& Laracy, 2013). Creating a learning environment for inclusive classrooms that is well managed with clear structures and routines is of the utmost importance for student success (Wong \& Wong, 2014).

The classroom management strategies that will be offered in this article are basic to any inclusive classroom. While tomes have been written on classroom management, the strategies presented are often tied to creating points systems, requiring too much additional effort on the part of teachers to implement and maintain over time. Typically if we can get teachers to adopt such a strategy, they soon realize that the use of "points systems" requires a tremendous "bookkeeping effort". Further, the need to vary reinforcers and fund the purchase of these reinforcers presents additional challenges. Over time, teacher use of points systems will begin to wane because these systems can be burdensome and costly.

Once the management system begins to appear inconsistent, the students receive a clear message that violating classroom rules and norms may not be met with consequences with any consistency. This absence of consistency functions as a "disinhibition effect" and may contribute to students engaging in more inappropriate behavior over time to test the limits. For teachers, effective classroom management and the consistency that is required are rooted in the statement "say what you mean and mean what you say!”. According to Wong and Wong (2014), consistency is an important key to success.

\section{Creating a Reinforcing Classroom Environment}

Creating a climate conducive to students complying with behavioral expectations, volunteering answers or taking on more challenging assignments is closely tied to the "emotional temperature" of the classroom. Students need to know that if they take a risk and respond to a challenging question or assignment, they will be "safe" from criticism. "School must be a safe and protected environment, where a student can come and learn without fear” (Wong \& Wong, 2014: p. 11). A classroom where the "emotional temperature" is warm and congenial is a classroom where students will be more willing to take on academic and/or behavioral challenges-more willing to venture a bit outside their comfort zone.

How do we create this safe and emotionally warm environment? The answer is closely linked to the ratio of teacher approvals to disapprovals that occur throughout the day. In classrooms where teachers are high approval (very reinforcing), they recognize appropriate behavior and acknowledge such acts verbally with a high degree of frequency. Research on the ratio of approvals to disapprovals emitted by teachers in a variety of classroom settings indicates that most classrooms are high disapproval (very punitive) (Polirstok \& Greer, 1977). High disapproval teacher behavior over time can often serve to maintain high levels of inappropriate behavior. On its face, this statement seems odd because being admonished should serve to lessen the frequency of inappropriate behavior. However, if students are accustomed to receiving negative feedback almost exclusively, providing such attention, serves to not only maintain the existing inappropriate behavior but may actually contribute to an increase (Scott, Anderson, \& Alter, 2012). By issuing a disapproval immediately following an undesirable behavior, the disapproval can function not as an intended inhibitor of the problematic behavior, but inadvertently as a reinforcer. For students whose reinforcement history outside of school has typically been negative, they are likely to seek negative attention from their teachers.

Unwittingly teachers often find themselves caught in a "cycle of mutually aversive behavior", the more the teacher tries to limit inappropriate behavior through the use of disapproval or punishment, the more the behavior surges or asserts itself. This cycle of interaction could be thought of as a "dance of anger", which can continue to escalate over time. Such a cycle of interaction could create an environment where teachers and students may well engage in confrontational behaviors which can readily escalate into serious behavioral incidents. Classrooms where the emotional temperature is hostile can be characterized by this "dance of anger" and teachers who are caught in such cycles leave at the end of each day emotionally drained. According to Scheuermann and Hall (2012), “changing inappropriate student behavior requires changing the teacher’s behavior”(p. 21).

In classrooms where the teachers are high approval, the students acknowledge that approval by increased smiles, hand rising, sustained eye contact, and/or increased on task time. Similar to the disapproval cycle discussed previously, a different cycle of interaction develops. This cycle is characterized by "mutually pleasing 
interactions", and these classrooms are places where teachers and students leave at the end of the day feeling very positive. If the cycles of interaction are mutually pleasing, we see classrooms that are very warm emotionally and students who are willing to take risks and try things that might be difficult because they believe that the teacher will not provide comments that would be personally embarrassing, negative or hostile. Conversely, if the "cycles of interaction are mutually aversive", then the emotional temperature in the classroom would be highly negative and students would be less willing to engage in anything that would be pro-academic or behaviorally appropriate.

What we learn from these cycles is that approval and disapproval are reciprocal; approval begets more approval and disapproval begets more disapproval. Cycles of interaction that are either mutually pleasing or mutually aversive can develop (Polirstok \& Greer, 1977; Polirstok \& Gottlieb, 2006). Given this understanding of approval and disapproval, the key to maintaining an emotionally warm environment is to keep disapproval comments to students to a minimum. In order to accomplish such a task, a technique known as "selective ignoring" needs to be utilized.

\section{Using Selective Ignoring}

Selective ignoring may be one of the most difficult techniques to learn. Short of students being engaged in behaviors that would be "harmful to self" or "harmful to others", the teacher always has a choice as to how to respond to inappropriate behavior. Through the teacher's lens, the key question is whether the glass is half full or half empty? "Using planned ignoring is a consequence strategy to reduce minor misbehaviors in an invaluable part of a teacher's repertoire” (Scott, Anderson, \& Alter, 2012: p. 239). It's all about the teacher's perspective and the end goal in mind. Here are some choices the teacher might make:

- Should the teacher provide disapproval comments about the problematic behavior? Or

- Should the teacher ignore the inappropriate behavior? Or

- Should the teacher ignore the inappropriate behavior? "Catch other students being good?” and Provide approval for their appropriate behaviors?

If you selected the last choice, you are correct! Providing positive feedback or approval for appropriate behavior reinforces classroom expectations. Teachers fail to understand that disapproval does not teach the target behavior- “disapproval teaches what not to do". Using selective ignoring is only part of the process. Approving students for engaging in the correct behavior reinforces expectations and gives the students who are engaging in the problematic behavior an opportunity to not only see the correct behavior, but to see their peers earning reinforcement for that behavior.

However, if students are engaging in behaviors that are harmful to self or harmful to others, this cannot be ignored. The teacher has little choice but to provide verbal feedback that is disapproving to inhibit the behavior. If the disapproval doesn't work, then the student or students need to be removed from the classroom for their dangerous behaviors. If the students who are engaged in harmful behavior refuse to leave the classroom (and that sometimes happens), then the teacher's next action would be to remove all of the other students from the potential danger in the classroom and bring them out to the hallway while help is summoned.

Using selective ignoring provides teachers with an opportunity to focus on appropriate behaviors and to recognize students for their compliance. By choosing to adopt this perspective, teachers can limit the constant negative barrage often seen in classrooms where teachers are continuously naming students who are off-task and noncompliant. Selective ignoring provides the teacher with an alternative strategy that can help to limit disapproval and focus on keeping the classroom emotionally safe and well regulated.

\section{Focusing on Structure and Routine}

Creating an emotionally safe classroom environment where students can be successful involves not only high approval interactions between students and teachers, but also requires an emphasis on structure and routine. There is safety for students, especially those with mild to moderate learning and behavioral challenges, in structure and routine. Helping student to learn the day to day expectations requires consistency in the daily routines (Wong \& Wong, 2014). Often teachers believe that teaching the routines and expectancies occur during the first weeks of school. In reality, routines and expectations are taught each day through the teacher's use of approval of student appropriate and compliant behaviors.

Any change in daily schedule or routine requires that the teacher prepare the student in advance to understand 
what change or changes will occur. For some students, reminders as to the change in schedule or routine need to occur for several days in advance of the change. For example, if there will be a special assembly program on Thursday morning, the teacher needs to announce this change every day leading up to the event. Not only is an announcement required, but a discussion with students about expectations for how they should manage their behavior for that special event is needed. What behaviors should the teacher discuss in advance?

- How should each student behave while the class walks in the hallway to the special assembly and then back to their classroom after the event?

- What behavior is expected when sitting in the assembly for a special program?

- What follow up classroom assignment will occur after the assembly (a cue for what students should pay close attention to) that students will be required to complete?

- How will the teacher reward students for their compliance with these expectations?

The more deliberately this advanced preparation is done, the greater the likelihood that the students will meet those expectations.

Structure and routine also involve behaviors that support academics. When giving instructions for assignments, teachers must be very deliberate and use this opportunity to reinforce listening skills on the part of the students. If the assignment requires several steps, the teacher might ask students what should be done first. What should be done next? What would be the final step? Asking students to repeat an answer or a direction just given helps reinforce the notion that everyone has something to contribute. Such a deliberate procedure will help to lessen "unwarranted questions about what should be done". Creating this listening opportunity helps to reinforce not only the task, but the students for attending to the direction giving process. As a consequence unwarranted questions will diminish and students will begin to ask better (warranted) questions about the task itself.

When selecting academic tasks for students to do independently at their seats, the teacher must be confident that each student has the ability to do the task that is assigned to him or her without needing continuous teacher attention and support. By definition, doing a task at one's independent level would require little to no additional teacher input. There needs to be a good fit between the student's ability and the demands of the task for independent at-seat work. Choosing the right independent tasks for students depends on a teacher's understanding of the difference between independent, instructional and frustration levels of student reading as per Lipson and Wixson (1991):

- A student at the independent level can decode $95 \%$ or more of the reading material and comprehends $90 \%$ or more.

- A student at the instructional level can decode $90 \%$ - $94 \%$ of the selection, but comprehends $75 \%$ - $90 \%$ or less.

- A student at the frustration level can decode $90 \%$ or less of the selection, but comprehends only $50 \%$ or less.

Understanding the differences between these levels can have a significant impact on the tasks teachers select for students to complete independently. Hence an independent assignment is one that a student can complete with little teacher direction. At the instructional level, a student may require much more teacher support. When a task is assigned that is not a good fit for a given student, at his/her frustration level, it is likely that the student will lose interest quickly, ask excessive questions, leave his/her seat without permission, and may engage in some inappropriate behavior that may warrant the student's removal from class. For many students, especially those with learning and behavioral challenges, being removed from class is preferable to having others note that you cannot complete the assigned task; a student may feel that it is always more preferable to be perceived as "big and bad" than perceived as "stupid."

It is precisely at moments like this when students are engaged in behaviors that may be confrontational with the intent (consciously or unconsciously) of avoiding the assigned task, that teachers need to be vigilant about not escalating the student behavior.

\section{De-Escalating Behavioral Crises}

When teachers are confronted by students who are verbally abusive and/or threatening, teachers need to be aware of their own responses to this behavior. When a teacher responds to a student's abusive behavior on a personal level and not on a professional level, the likelihood that the teacher might say or do something that would be less than professional is increased. It's important for teachers to maintain professional control and not respond on a personal level. When the controls are absent, teachers often respond to student verbal abuse and/or threatening behavior with hostility, thereby increasing the volume of the exchange and contributing to the 
"dance of anger" described earlier. If this exchange continues to be more and more hostile, then it may set the stage for the student to become physically aggressive.

To avoid the chance that a student could become aggressive and to avoid the chance that a teacher could say or do something that is less than professional, there are actions teachers can employ that can help to prevent the crisis from escalating:

- Teachers need to recognize that when the emotional temperature of the interaction is becoming heated, that they should drop their voice tone as one way of preventing a situation from escalating.

- Teachers should be cognizant not to move into the student's personal space. In the heat of an exchange, a teacher can lose control and violate a student's space, putting themselves at-risk for injury.

- Even if there is a reasonable space between the teacher and the student, the teacher should take a step back from the student so as not to be in range in case the student loses control and throws a punch.

- As the teacher moves out of the way, deliberately if possible, the teacher should lower hands to his/her side. This is a good visual cue to the student that they are not going to be physically threatened.

- While keeping the teacher's voice tone at a modulated level, the teacher should keep asserting what the student should do. Teachers need to remember that when students are agitated, less teacher talk is preferred. Use calm, focused language that is short and clipped; the less verbose the better. For example, the teacher might keep repeating "return to your seat; find your seat; sit down now." As long as the voice level is not increasing, repetition of the direction simply maintains the teacher's request without escalating the situation. "Repeating a 'what to do' with greater specificity" can be used effectively in a crisis situation (Lemov, 2010: p. 81).

- If the confrontation seems to have passed, then the teacher needs to give the student an opportunity to find the way back to his/her seat without "losing face."As soon as the student complies, the teacher needs to provide positive reinforcement for making a "good behavioral choice." Should the student not return to his/her seat, the teacher should remind the student that (s) he is not making a good choice and that the teacher will need to follow up with the student later. This statement is really an announcement for the rest of the class so that they understand that the teacher is well aware of what rule(s) the student is violating and that there will be consequences, albeit just not at that very moment.

\section{Increasing Student Locus of Control}

An important component of classroom management is helping students to recognize that some of the choices they make regarding their behaviors are better than others. When they make good choices, these need to be reinforced and celebrated. When they make poor choices, they need to understand why what they chose to do is a poor choice and what alternative responses they could have chosen that would have been better choices. For many included students who have learning and behavioral challenges, accepting responsibility for the choices they make is identified in the behavioral literature as "internal locus of control". Most students with learning and behavioral challenges typically blame others or external factors for the problematic choices they make-it's everyone else's fault, certainly not theirs! This is referred to in the behavioral literature as having an "external locus of control".

Part of the confusion for students is that they typically have difficulty discriminating what the behavioral expectations are in different settings. As a consequence, they may "overgeneralize" a way of behaving that may be appropriate in one setting but is definitely not appropriate in another. For example, if students are out of school on the weekend and speaking to each other using language that would be considered "inappropriate", it might be okay given that they are in a less than formal setting. On the other hand, when in school or at a job site or in a place of worship, such language would not be appropriate. So good behavioral choices begin when students can discriminate between the behavioral demands and expectations of different settings (Polirstok \& Gottlieb, 2006; Polirstok \& Houghteling, 2006).

In inclusion classes, there are many students with mild to moderate learning and attention disorders who have an external locus of control (Tarnowski \& Nay, 1989). A teacher who is working to improve student independent function needs to help students begin to shift the locus of control from an external focus to an internal focus. How can a teacher accomplish this? There are some steps, which if applied consistently over time can help students to accept more responsibility for their choices. Here are some steps to follow:

- Begin by asking a student to explain the problem behavior and what happened.

- Have the student identify what classroom or school rule was violated in this incident. 
- Explore other options for responding to the same situation the next time.

- Once these alternative behavioral choices are identified, then the question becomes: What's the best choice? What's the $2^{\text {nd }}$ best choice? What's the worst choice? Why?

By following this kind of procedure, teachers are able to help students recognize that behavior is situationally governed and that one way of responding may not be appropriate given different demands by setting. The most important element in this procedure is the question about the next time a specific situation presents itself. Good behavioral intervention should always be focused on how to improve the next time (Polirstok, 2010).

\section{Limiting the Use of Punishment}

Most classroom management systems usually over rely on the use of punishment. Students with attention deficit problems often present with reduced sensitivity to rewards and punishments, a neurological consequence of the disorder. Over time, teachers will feel the need to keep increasing punishments in severity or duration because mild punishment doesn't seem to be having the desired effect on students with attention deficits. The problem with this approach is that over use of punishment does not teach the target behavior and engenders resentment on the part of students. In the behavioral literature, mild aversive punishment produces avoidant behavior, not the outcome one would hope for in helping students learn to behave more appropriately. The key for teachers is to predominantly use positive behavior supports and strategies; punishment can work only if it is used sparingly.

All too often, classroom teachers use punishment strategies as a first option in managing challenging behavior. That translates into teachers saying the following things to students "if you continue this behavior, you can't go on the trip on Friday", "you just lost 15 minutes of recess time”, “you won't be able to participate in the art show next week", etc. Most of the time when privileges are lost, they are typically activities that involve the arts, or physical education, or some school event or service. These are the very activities that students with learning and behavior disorders look forward to the most in their school day because they are less academic and students tend to excel in these activities. Overreliance on removing privileges or favored activities like these carries emotional resentment and produces "punishment resistant kids". When students have nothing left to lose like privileges they have earned or points they have acquired for following the rules, students can become resentful and deliberately challenge authority (Scott, Anderson, \& Alter, 2012).

Whatever management system you have in place, the goal is to let the student earn the privileges or reinforcers so that they can have a positive experience with following the rules or with improving their academic achievement. Pulling reinforcers or privileges away comes with an emotional cost (Zirpoli, 2012). Students who work hard to earn these reinforcers are resentful when they lose them. Instead of the "take away approach" teachers need to clarify that when students engage in inappropriate behavior, they lose the opportunity to earn reinforcers or privileges going forward, but should not lose reinforcers or privileges for what they have already earned. This is more than a semantic difference; it represents a difference in philosophy that effective teachers embrace. While students may miss opportunities to earn privileges or reinforcers, as soon as they begin to behave more appropriately, it will be the teacher's job to "catch them being good" and provide them with reinforcement for their compliance.

\section{Conclusion}

The strategies that have been presented in this article provide an approach to classroom management that is relatively easy to implement. The key ingredient in this approach is teacher fidelity to the behavioral expectations that have been established for students. A teacher cannot choose to use selective ignoring and catch students being good on Monday and then fail to do just that for the remainder of the week. What makes this approach work is teacher consistency with his/her use of approvals and teacher disapprovals in response to student behavior, a commitment to structure and routine, and a belief that students can be taught to take responsibility for their own actions. Changing the approval-disapproval ratio in classrooms can go a long way towards making teaching and learning fun!

\section{References}

DuPual, G., Gormley, M., \& Laracy, S. (2013). Comorbidity of LD and ADHD: Implications of DSM-5 for Assessment and Treatment. Journal of Learning Disabilities, 46, 43-51. http://dx.doi.org/10.1177/0022219412464351 
Lemov, D. (2010). Teach Like a Champion. San Francisco, CA: Jossey-Bass.

Lipson, A., \& Wixson, K. (1991). Assessment and Instruction of Reading Disability: An Interactive Approach. New York, NY: HarperCollins.

Polirstok, S. (2010). Developing Emotional Intelligence in Children and Adolescents with Nonverbal Learning Disabilities and Attention Deficits: Strategies for Teachers and Parents. Educating the Creative Mind Conference Proceedings, Union, NJ: Kean University, 77-83.

Polirstok, S., \& Gottlieb, J. (2006). The Impact of Positive Behavior Intervention Training for Teachers on Referral Rates for Misbehavior, Special Education Evaluation, and Student Reading Achievement in the Elementary Grades. International Journal of Behavioral and Consultation Therapy, 2, 354-361. http://dx.doi.org/10.1037/h0100789

Polirstok, S., \& Greer, R. (1977). Remediation of Mutually Aversive Interactions between a Problem Student and Four Teachers by Training the Student in Reinforcement Techniques. Journal of Applied Behavior Analysis, 10, 707-716. http://dx.doi.org/10.1901/jaba.1977.10-707

Polirstok, S., \& Houghteling, L. (2006). Asperger Syndrome: A Primer for Behavioral Interventionists. Journal of Early and Intensive Behavioral Intervention, 3, 187-195. http://dx.doi.org/10.1037/h0100331

Scheuermann, B., \& Hall, J. (2012).Positive Behavioral Supports for the Classroom (2nd ed.). Upper Saddle River, NJ: Pearson.

Scott, T., Anderson, C., \& Alter, P. (2012). Managing Classroom Behavior Using Positive Behavior Supports. Upper Saddle River, NJ: Pearson.

Tarnowski, K., \& Nay, S. (1989). Locus of Control in Children with Learning Disabilities and Hyperactivity: A Subgroup Analysis. Journal of Learning Disabilities, 122, 381-383. http://dx.doi.org/10.1177/002221948902200610

Wong, H., \& Wong, R. (2014). The Classroom Management Book. Mountainside, CA: Wong Publishing.

Zirpoli, T. (2012). Behavior Management: POSITIVE Applications for Teachers (6th ed.). Upper Saddle River, NJ: Pearson. 